\title{
Solutions and Recent Challenges Related to Energy in Wireless Body Area Networks with Integrated Technologies: Applications and Perspectives
}

\author{
Yousra Abdul Alsahib S.Aldeen ${ }^{1 *}$ \\ Kashif Naseer Qureshi ${ }^{2}$
}

Received 27/1/2019, Accepted 8/7/2019, Published 18/3/2020

\begin{abstract}
:
In this paper, we have investigated some of the most recent energy efficient routing protocols for wireless body area networks. This technology has seen advancements in recent times where wireless sensors are injected in the human body to sense and measure body parameters like temperature, heartbeat and glucose level. These tiny wireless sensors gather body data information and send it over a wireless network to the base station. The data measurements are examined by the doctor or physician and the suitable cure is suggested. The whole communication is done through routing protocols in a network environment. Routing protocol consumes energy while helping non-stop communication in a wireless environment. Because of the very tiny size, energy consumption matters a lot. We have focused on the protocols, which provide energy efficiency and improve network lifetime, through put and minimal path loss. We will be discussing some of the most recent energy efficient routing protocols in this paper; later their comparison with an appropriate table is presented. In addition, recent challenges, possible application and perspectives are discussed.
\end{abstract}

Key words: Cluster Heads, Energy Efficiency, Routing Protocols, WBAN, WSN.

\section{Introduction:}

Wireless Body Area Networks (WBANs) is an emerging and fast-growing field. Research has been done over this domain to make it secure, efficient and economical with reliability and authenticity. The smart sensors have capabilities to place on or inside the human body and calculate different measurements of temperature, heat and any abnormal activity of diseases (1). This area is much more being created day by day to improve the quality of health services as well as much more security and economy (2). These tiny wireless sensors are injected inside or outside of the body to detect and measures the data and then send to a Base Station (BS) through wireless technologies. Based on the calculated data, the physicians detect what cure to be given to the patient (3). This process is very fast and effective as it is timesaving as well as fast because it detects the disease and the patient can be cured as soon as possible. There are some devices that are involved in the whole process like sensors, personal digital assistant and smartphones or computer systems, which are

${ }^{1}$ Department of Computer Science, College Of Science for Women, University of Baghdad, Baghdad, Iraq.

${ }^{2}$ Department of Computer Science, Bahria University, Islamabad, Pakistan

"Corresponding author: yousraalkaalesi@gmail.com *ORCID ID: 0000-0003-3178-8665 connected to each other through wireless networks.

The focus of users is on smooth and efficient WBANs schemes which provide us the most efficient services and systems to implement (4). For this purpose, we must focus on energy efficiency and reliable transmission of data among sensor nodes over the wireless networks. Fig. 1 shows the WBANs communication process.

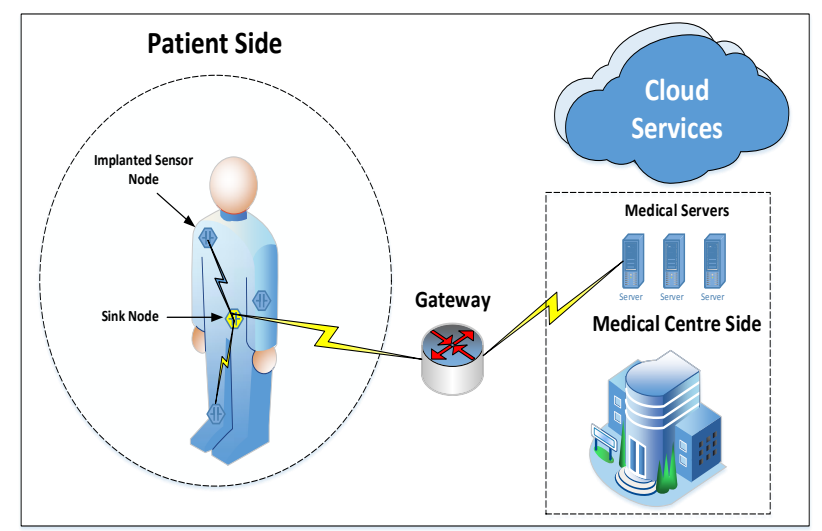

Figure 1. WBANs Communication Process

With various advantages, WBAN has some limitations and challenges related to security, energy consumption, routing and scalability (5). The sensor nodes are planted inside or outside the patient body and communicate through sink nodes. 
Sink nodes have more capability to process the data routing among sensor nodes and forward sensed data to base station or medical centers. The sink node works as a controller or gateway. The main objective of sensor nodes is passing the data in time without any delay for further decision. The sensed data is related to patient conditions including heart rate, blood pressure and temperature. Routing protocols have main role for data processing (6). The protocols main objectives are to find the shortest path, consume less energy and provide high throughput in the network. In order to fulfill the network requirements, various routing protocols have been designed based on different strategies ( 7 , 8).

In this paper, our focus is on some of the very important techniques related to tackle the energy efficiency problems for WBAN system process. We will study the recent studies on the topic of energy efficiency and discuss the more suitable and latest research work. This paper discusses all the aspects relating to the WBANs. We will derive the problems associated with WBAN in different aspects and environments as well as present the comparative analysis of the different studies of WBANs.

The rest of the paper is organized as follows: Section 2 discusses the recent communication technologies used in WBANs. Section 3 presents the existing and implemented applications in this domain. Section 4 shows the recent challenges. Recent solutions and comparison study are presented in Section 5. The last section concludes the paper with future direction.

\section{Integrated Technologies}

There are various different types of radio technologies that have been implemented to make the applications more feasible and reliable. The WBANs applications are based on different frequency bands of communication channels for intra and inter-body communication. Antenna based radio frequency is used to transmitting the signals to the antenna via the patient body to external devices. In 1999, the radio frequency standard has been developed by the Federal Communication Commission (FCC) (9). Another technology is medical devices for radio communication, which involve implanting communication systems within the human body. This standard uses $402-405 \mathrm{MHz}$ frequency band with $300 \mathrm{kHz}$ bandwidth per channel. Inductively coupled data communication among variable devices are achieved through mutual induction coils. Different frequencies have been adopted for induction such as $5-10 \mathrm{MHz}, 24$ $\mathrm{MHz}$ and $49 \mathrm{MHz}$ (10).

\section{Applications}

There are various types of applications which have been designed for WBANs to measure the vital signs of the human body. The implants sensor nodes measure the vital health signs and treat some form of ailment via electromagnetic stimulation or target of the biochemical intervention and give close feedback to other implanted sensor nodes. The applications are categorized into diagnostic, therapeutic and assistive technology. The diagnostic applications are used for glucose, oximeter, $\mathrm{pH}$ and gastrointestinal imaginary sensor nodes. The therapeutic applications are used as pacemaker, deep brain stimulator and nerve and muscle stimulator sensor nodes. The third type of assistive technology is based on cochlear implants, bionic vision, brain interface and prosthetic limbs monitoring (11).

\section{Challenges}

There are various challenges faced by WBANs applications including energy, interference, routing, latency, and scalability, and network coexistence, quality of services, low cost, reliability and security. Energy consumption is one of the main and significant challenges especially for the implant of sensor node, which need surgery for battery replacement. Energy consumption problem is mostly depending on sensing, communication and data processing of sensor nodes. Due to interference and human body movement, the communication among sensor node and personal devices are more complex and consume more energy. Idle listening and over the hearing of data packets need highsecurity requirements (12).

\section{Existing Solutions}

Our world is getting smaller, globalization may be the predominant factor, but, for us, wireless sensor networks are opening new avenues to squeeze the resources and generate relevant data in huge amounts to help us make better and informed decisions. Wireless Sensor Networks (WSNs) are not only cheap and easy to deploy but also efficient in nature and easy to maintain. Their applications cover horizon to horizon ranging from health, mobility, tracking and industrial usage. Wireless Body Area Networks is a sub-branch in this domain of WSNs focusing on health and wellbeing applications. While WBANs inherit the strengths of their parents (WSNs), they also inherit their weaknesses. WBANs consist of miniature nodes with limited computation and energy resources along with a specific task involving sensing a signal (temperature, pressure, pollutants, etc.). One of the major problems faced by such localized networks are energy constraints as most of the times are equipped with non-chargeable power sources. On 
analysis, it can be easily determined that the most resource hungry operation in a WBAN node is routing. Routing includes finding a network path and transmission of data along that path. Clustering is used to overcome this resource constraint in WBAN routing; clustering is pairing and division of nodes to induce energy efficiency and cut short latency (13).

In this model, a cluster head identifies who is responsible for relaying the data gathered from all the nodes. The cluster head is more resource intrinsic than the remaining nodes, with such pairing an equilibrium is achieved where the nodes are energy efficient and the cluster head, which has more energy resources as compared to the cluster nodes, which spend more energy. The cluster nodes know the definite path to the cluster head hence low energy consumption in resource routing.

Apart from cluster-based algorithms, many other algorithms have been devised to cater to the energy efficiency issue in WBANs. In almost all the cluster-based algorithms, the cluster heads are responsible for gathering the data from the cluster nodes and then relaying the information to the base station. The major algorithms (LEACH, HEED etc.) work fine in a homogenous environment but struggle to perform in a heterogeneous environment. Another clustering algorithm PEGASIS forms a chain from the nodes by assistance from the base station. In the HEED clustering algorithm, the cluster heads are selected probabilistically on the energy of the nodes. Another methodology is to divide the complete networks into unequal networks based on overall energy utilization of the complete local network. In addition, the proposed CBBAP protocol works based on cluster formation, cluster heads (CHs), gateway and static BS outside the network. Furthermore, the simulation-based research showed significant improvement than LEACH protocol for WBAN such as energy efficiency improvement between $25-35 \%$ in WBANs by increasing overall energy efficiency, lifetime, throughput and residual energy. Kurian and Divya (14) presented a thorough structure of routing efficiency in wireless sensor networks and wireless body area network in her research work. Major concerns of the research are how to increase the energy efficiency, different routing techniques were studied and compared with each other to what best suits the system. The routing protocols were generalized in different standards as if they were cluster based, cross-layer based, probabilistic based and temperature based. Almost all factors like temperature, link, routing matrices etc. were kept in mind during the study and experiments. LAEEBA and Co-LAEEBA were efficient in energy efficiency as these protocols link aware protocols. Among iM-SIMPLE with energy and M-ATTEMPT providing thermal aware routing protocols, Co-LAEEBA with cooperative based routing approach was considered better. LAEEBA is also a protocol being used for energy efficiency in wireless body area networks. LAEEBA is a link aware routing protocol minimizing the path loss and increasing the throughput. The cost function is the factor to select the nearest node, which acts as a forwarder of data to the surrounding nodes in wireless body area networks. To consume energy efficiently, the residual energy function is used, it helps to stay longer and maximizes the network lifetime. In LAEEBA two in the eight nodes forward data from the selected parent nodes to the other nodes, which are called child nodes. S.

Ahmed, Javaid (15) has worked on how to increase the performance of Co-LAEEBA routing protocol with some of the factors which are residual energy, throughput, delay spread, stability period, network lifetime and path-loss. The research proposed some mechanisms, which consider both single and multi-hops to route data over link aware routing protocols in wireless body area networks. The cost function was proposed to check the best route available for data sharing. Complete information about distance and residual energy is shared from a node to sink in the architecture. It is considered an effective protocol for energy efficiency in WBAN. Fig. 2 shows the typical model for WBAN.

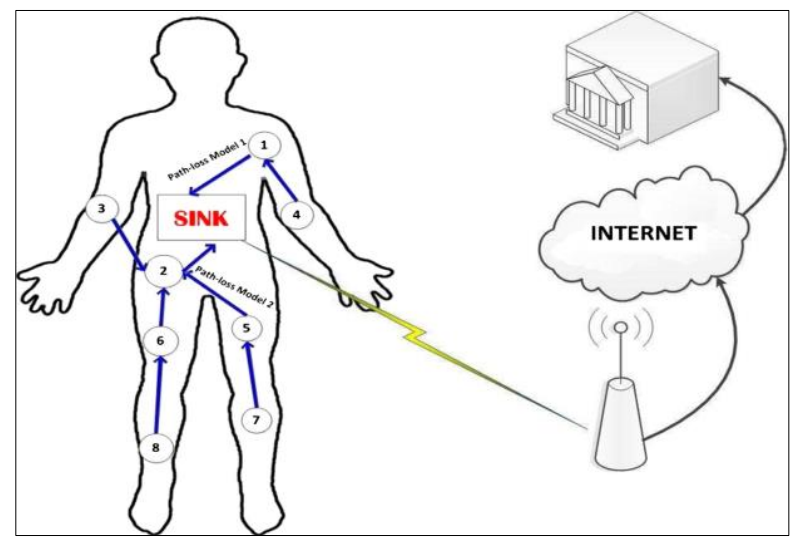

Figure 2. A typical WBAN Model

Javaid, Ahmad (16) worked on SIMPLE routing protocol and presented an extended SIMPLE protocol naming iM-SIMPLE. It supports mobility in the architecture while the forwarder node is selected based on cost function, which depends on residual energy and its distance from the sink node. The node, which is mostly the nearest to the sink, is selected as forwarder and the other nodes become children nodes of the nearest node, 
which is called parent node. Parent node shares the data over the network to all connected nodes, which are children nodes. Energy consumed is calculated which is better than SIMPLE and M-ATTEMPT. M-ATTEMPT (17) is heterogeneous routing algorithm for WASNs. In this protocol, the desired and demanded data is directly transmitted over to the sink while other traffic is multi-hop. It is a thermal aware protocol, which senses the link hot spot and share the data over to the other nodes in the architecture. RE-ATTEMPT protocol also overcomes some of the issues in single and multihop routing in WBSNs. The delay in multi hop is minimized by minimum hop count. While highenergy consumption is reduced by minimizing, relay nodes and equating the distance as well as their energy distribution. Also provided in the paper are time domain, problem formulation and its solution.

Sandhu, Javaid (18) presented a routing protocol, which is balanced energy consumption BEC protocol. It works on relay node systems; cost function here is also the main factor to select a relay node. Relays communicate to the nearest nodes and to the sink nodes in the network architecture. Only critical data information is shared when energy is less than the threshold level. This protocol also considers stability period and network lifetime, network throughput, path loss, residual energy. This BEC protocol also presents a suitable mechanism for energy efficiency in WBAN.

Sandhu, Javaid (19) presented a FEEL protocol which is based on forwarding data energy with load balancing. All nodes send their data to the forwarder, which then takes the responsibility to the sink node. Forwarder link has the maximum residual energy. It directly sends critical data like ECG and Glucose level to the sink node while not deleting energy very soon. Thus, lasting longer, improving network lifetime and minimizing path loss.

Lee, Lee (20) presented a cluster-based energyefficient routing protocol for WBAN, which also overcomes the existing issues to make network lifetime last longer and decreasing energy consumption in the WBAN environment. This protocol is based on Ant Colony Optimization Meta heuristic scheme. In this scheme ACO probabilistic hierarchy, considering pheromones and residual energy selects the optimal path. Data is monitored and sent to base station continuously improving network performance and reducing the overhead in the WBAN environment.

As the literature already in discussion, energy efficiency is very important for WBANs in routing protocols. Yi, Wang (21) has discussed the effects of moving nodes on the energy efficiency of the routing protocols in WBAN. Based on the analysis of distance over routing data over that distance a tradeoff could be achieved to minimize the energy loss and maximize the energy efficiency. Based on this technique much energy could be spared in this routing methodology. This could also be extended into battery aware energy efficiency protocols, which take into account battery properties. The tradeoff in this scenario is the offline algorithm, which optimizes the energy balance between mobile, stationary, sink and expanding nodes.

Kumar \& Singh (18) worked on the shortest path between the sender and receiver node with offline algorithm and direct analysis based on sensor nodes. The information is retained, and the routing choices are made based on this retained value. It was shown through simulations that the duty cycle increases by more than $10 \%$ based on this but the performance is decreased when the number of nodes and mobility of nodes increases, the performance is quite diminished when the nodes increase by 100 and the distance between nodes increase the estimated distance. The relative positioning of the nodes plays an important part in the performance as well which is directly proportional to energy losses when the relative positions change based on the offline analytical values stored initially in the algorithm. The algorithm is not best suited for mobile nodes. K. N.

Qureshi, Bashir (22) proposed energy and link aware routing protocol for the next hop selection in WBAN environment. It is based on neighbor nodes selection comprising the parameters like energy level and link quality. This ELA-RP protocol provides a balanced energy consumption and minimal data delay, thus; increasing data delivery in the network. The results are very much effective in proving a better mechanism of the network model, energy consumption, data delivery and low delay.

\section{Comparative Analysis}

Based on the literature review, a comparative analysis was made to show the modus operandi of the literature and their benefits over the other. Table 1 presents the comparison analysis of discussed protocols in paper. 
Table 1. Protocols Comparison Analysis

\begin{tabular}{|c|c|c|c|c|c|}
\hline S.No & Existing Solution & Adopted Strategy & Goal & Strength & Limitation \\
\hline 1 & $\begin{array}{l}\text { CBBAP (Turki Ali } \\
\text { Alghamdi, 2016) }\end{array}$ & Clustering & $\begin{array}{l}\text { Address energy } \\
\text { consumption issue. }\end{array}$ & $\begin{array}{l}\text { Provide distributed } \\
\text { environment where } \\
\text { initial energy is } \\
\text { considered at same } \\
\text { levels. }\end{array}$ & $\begin{array}{l}\text { Formation of } \\
\text { clustering consumes } \\
\text { more processing and } \\
\text { cause of energy } \\
\text { consumption. }\end{array}$ \\
\hline 2 & $\begin{array}{l}\text { LAEEBA (S. } \\
\text { Ahmed et al., 2014) }\end{array}$ & $\begin{array}{l}\text { Single-Multi hop, } \\
\text { Communication, } \\
\text { Cost Functions for } \\
\text { Data Forwarding }\end{array}$ & $\begin{array}{l}\text { To find shortest } \\
\text { path. }\end{array}$ & $\begin{array}{l}\text { Link awareness and cost } \\
\text { function-based routes } \\
\text { for sink node selection. }\end{array}$ & $\begin{array}{l}\text { The mobility of } \\
\text { patient is not taking } \\
\text { into account. }\end{array}$ \\
\hline 3 & $\begin{array}{l}\text { Co-LAEEBA (S. } \\
\text { Ahmed et al., 2015) }\end{array}$ & $\begin{array}{l}\text { Single-Multi hop, } \\
\text { Communication, } \\
\text { Cost Functions for } \\
\text { Data Forwarding }\end{array}$ & $\begin{array}{l}\text { To find shortest } \\
\text { path. }\end{array}$ & $\begin{array}{l}\text { Through cost functions } \\
\text { routes are selected and } \\
\text { calculate residual } \\
\text { energy. }\end{array}$ & $\begin{array}{l}\text { Cost function } \\
\text { consumes more } \\
\text { processing power. }\end{array}$ \\
\hline 4 & $\begin{array}{l}\text { SIMPLE (N. Javaid } \\
\text { et al., 2014) }\end{array}$ & $\begin{array}{l}\text { TDMA Time slots } \\
\text { Strategy. }\end{array}$ & $\begin{array}{l}\text { Address energy } \\
\text { consumption issue } \\
\text { and improve } \\
\text { network lifetime. }\end{array}$ & $\begin{array}{l}\text { TDMA time slots are } \\
\text { used for child nodes to } \\
\text { forward their data to the } \\
\text { parent and to the sink } \\
\text { nodes. }\end{array}$ & $\begin{array}{l}\text { Data priority is not } \\
\text { taking into account. }\end{array}$ \\
\hline 5 & $\begin{array}{l}\text { iM-SIMPLE (N. } \\
\text { Javaid et al., 2014) }\end{array}$ & $\begin{array}{l}\text { Calculate nodes } \\
\text { distance and } \\
\text { residual energy, } \\
\text { Cost function }\end{array}$ & $\begin{array}{l}\text { Address energy } \\
\text { consumption issue } \\
\text { and improve } \\
\text { network lifetime. }\end{array}$ & $\begin{array}{l}\text { Using cost function } \\
\text { which is based on nodes } \\
\text { distance from the sink } \\
\text { and its residual energy. }\end{array}$ & $\begin{array}{l}\text { More parameters } \\
\text { consume more } \\
\text { processing power } \\
\text { and cause of energy } \\
\text { consumption }\end{array}$ \\
\hline 6 & $\begin{array}{l}\text { ATTEMPT (N. } \\
\text { Javaid et al., 2013) }\end{array}$ & $\begin{array}{l}\text { Parent and child } \\
\text { layers strategy, } \\
\text { Calculates data } \\
\text { rate. }\end{array}$ & $\begin{array}{l}\text { Address energy } \\
\text { consumption issue } \\
\text { and improve } \\
\text { network lifetime. }\end{array}$ & $\begin{array}{l}\text { Parent Nodes forward } \\
\text { the data to the child } \\
\text { nodes and thus to the } \\
\text { second level child nodes } \\
\text { improving network } \\
\text { lifetime. }\end{array}$ & $\begin{array}{l}\text { Recalculation of } \\
\text { data rate and uses } \\
\text { multi-layer cause of } \\
\text { overhead. }\end{array}$ \\
\hline 7 & $\begin{array}{l}\text { M-ATTEMPT (N. } \\
\text { Javaid et al., 2013) }\end{array}$ & $\begin{array}{l}\text { Single-Multi hop, } \\
\text { Communication, } \\
\text { TDMA Slots }\end{array}$ & $\begin{array}{l}\text { Address energy } \\
\text { consumption issue } \\
\text { and improve data } \\
\text { delivery. }\end{array}$ & $\begin{array}{l}\text { Data transmission by } \\
\text { sensing the links hot- } \\
\text { spot. Time Division } \\
\text { Multiple Access } \\
\text { scheduling is used to } \\
\text { communicate in the } \\
\text { network. }\end{array}$ & $\begin{array}{l}\text { Data priority is not } \\
\text { taking into account. }\end{array}$ \\
\hline 8 & $\begin{array}{l}\text { Re-ATTEMPT } \\
\text { (Ahmed et al., 2014) }\end{array}$ & $\begin{array}{l}\text { Calculate energy } \\
\text { level of nodes. }\end{array}$ & $\begin{array}{l}\text { Consuming low } \\
\text { energy and } \\
\text { maximizing } \\
\text { network lifetime. }\end{array}$ & $\begin{array}{l}\text { Placing nodes according } \\
\text { to their energy levels, } \\
\text { then to communicate } \\
\text { and find alternates when } \\
\text { some nodes are dead. }\end{array}$ & $\begin{array}{l}\text { Finding alternate } \\
\text { routes consumes } \\
\text { more energy. }\end{array}$ \\
\hline 9 & $\begin{array}{l}\text { FEEL (M. M. } \\
\text { Sandhu et al., 2014) }\end{array}$ & $\begin{array}{l}\text { Calculate Residual } \\
\text { Energy, Direct } \\
\text { Communication }\end{array}$ & $\begin{array}{l}\text { Improving network } \\
\text { lifetime and } \\
\text { minimizing path } \\
\text { loss. }\end{array}$ & $\begin{array}{l}\text { It directly sends critical } \\
\text { data to the sink node. }\end{array}$ & Overhead \\
\hline 10 & $\begin{array}{l}\text { BEC (M. Moid } \\
\text { Sandhu et al., 2015) }\end{array}$ & $\begin{array}{l}\text { Selection of Relay } \\
\text { nodes for data } \\
\text { forwarding, Cost } \\
\text { Function }\end{array}$ & $\begin{array}{l}\text { Minimizing energy } \\
\text { consumption }\end{array}$ & $\begin{array}{l}\text { Receive and forward the } \\
\text { data to the sink node and } \\
\text { relay nodes selected } \\
\text { dynamically to } \\
\text { minimizing energy } \\
\text { consumption. }\end{array}$ & $\begin{array}{l}\text { Disconnectivity and } \\
\text { link breakage. }\end{array}$ \\
\hline 11 & $\begin{array}{l}\text { CBEERP/ACOBAN } \\
\text { (Young Haan Lee et } \\
\text { al., 2017) }\end{array}$ & $\begin{array}{l}\text { Clustering, Ant } \\
\text { Colony } \\
\text { Optimization }\end{array}$ & $\begin{array}{l}\text { Minimizing energy } \\
\text { consumption, } \\
\text { Improve network } \\
\text { lifetime }\end{array}$ & $\begin{array}{l}\text { In this scheme the } \\
\text { optimal path is selected } \\
\text { by ACO probabilistic } \\
\text { hierarchy considering } \\
\text { pheromones and residual } \\
\text { energy. }\end{array}$ & $\begin{array}{l}\text { Ant colony is not } \\
\text { optimal for } \\
\text { WBANs. }\end{array}$ \\
\hline 12 & $\begin{array}{l}\text { ELA-RP (K. N. } \\
\text { Qureshi et al., 2018) }\end{array}$ & $\begin{array}{l}\text { Calculate Energy } \\
\text { Level, Link } \\
\text { Quality }\end{array}$ & $\begin{array}{l}\text { Improve Energy } \\
\text { consumption, } \\
\text { Improve data } \\
\text { delivery and low } \\
\text { data delay }\end{array}$ & $\begin{array}{l}\text { Determines parameters } \\
\text { like energy level and } \\
\text { link quality. }\end{array}$ & $\begin{array}{l}\text { Link breakage and } \\
\text { patient mobility } \\
\text { breaks the links. }\end{array}$ \\
\hline
\end{tabular}




\section{Conclusion:}

There are various different types of protocols, which are based on topology, geographical, and cluster-based approaches, which distinguish between their functionality. Every routing protocol has some uniqueness as well as some deficiencies. As we know, WBAN is inherited from WSN, so it inherits some of the demerits as well. The main challenge is energy consumption in WBAN environment. There are some of the recent presented protocols like ATTEMPT, M-ATTEMPT, RE-ATTEPT, SIIMPLE, IM-SIMPLE, BEC, LAEEBA, Co-LAEEBA, CBEERP/ACOBAN, FEEL and CBBAP which are implemented to enhance network lifetime and throughput. The main schemes widely used are Cluster Head and forwarding schemes. Cooperative Link aware mechanism also improves the energy efficiency. Both in Single-hop and Multi-hop environment the protocols have been developed to enhance the network throughput and life time by improving energy consumption.

\section{Conflicts of Interest: None.}

\section{References:}

1. Anwar M, Abdullah AH, Qureshi KN, Majid AH. Wireless Body Area Networks for Healthcare Applications: An Overview. TELKOMNIKA 2017;15(3):1088-95.

2. Abidi B, Jilbab A, Haziti ME. Wireless sensor networks in biomedical: Wireless body area networks. InEurope and MENA cooperation advances in information and communication technologies 2017 (pp. 321-329). Springer, Cham.

3. Awan K, Qureshi KN, Mehwish M. Wireless body area networks routing protocols: a review. Indonesian Journal of Electrical Engineering and Computer Science[IJEECS]. 2016;4(3):594-604.

4. Anwar M, Abdullah A, Altameem A, Qureshi K, Masud F, Faheem M, et al. Green Communication for Wireless Body Area Networks: Energy Aware Link Efficient Routing Approach. Sens. 2018;18(10):3237.

5. Chen $\mathrm{X}, \mathrm{Xu} \mathrm{Y}$, Liu A. Cross layer design for optimizing transmission reliability, energy efficiency, and lifetime in body sensor networks. Sens. 2017;17(4):900.

6. Waheed M, Ahmad R, Ahmed W, Drieberg M, Alam MM. Towards Efficient Wireless Body Area Network Using Two-Way Relay Cooperation. Sens 2018;18(2):565.

7. Kim B-S, Kim KH, Kim K-I. A survey on mobility support in wireless body area networks. Sens. 2017;17(4):797.

8. He D, Zeadally S, Kumar N, Lee J-H. Anonymous authentication for wireless body area networks with provable security. EEE SYST J. 2017;11(4):2590601.

9. Hayajneh T, Almashaqbeh G, Ullah S, Vasilakos AV. A survey of wireless technologies coexistence in
WBAN: analysis and open research issues. WIREL NETW. 2014;20(8):2165-99.

10. Howitt I, Gutierrez JA. IEEE 802.15. 4 low ratewireless personal area network coexistence issues. In2003 IEEE Wireless Communications and Networking, 2003. WCNC 2003. 2003 Mar 16 (Vol. 3, pp. 1481-1486). IEEE.

11. Teshome AK, Kibret B, Lai D. A Review of Implant Communication Technology in WBAN: Progresses and Challenges. RBME. 2018.

12. Yuce MR, Khan J. Wireless body area networks: technology, implementation, and applications: CRC Press; 2011.

13. Alghamdi TA. Cluster based energy efficient routing protocol for wireless body area networks. Trends Appl Sci Res. 2016;11(1):12.

14. Kurian A, Divya R. A survey on energy efficient routing protocols in wireless body area networks (WBAN). In2017 International Conference on Innovations in Information, Embedded and Communication Systems (ICIIECS) 2017 Mar 17 (pp. 1-6). IEEE.

15. Ahmed S, Javaid N, Akbar M, Iqbal A, Khan ZA, Qasim U, editors. LAEEBA: Link aware and energy efficient scheme for body area networks. 2014 IEEE 28th International Conference on Advanced Information Networking and Applications; 2014: IEEE.

16. Javaid N, Ahmad A, Nadeem Q, Imran M, Haider N. iM-SIMPLE: iMproved stable increased-throughput multi-hop link efficient routing protocol for Wireless Body Area Networks. Comput. Hum. Behav.. 2015;51:1003-11.

17. Ahmad A, Javaid N, Qasim U, Ishfaq M, Khan ZA, Alghamdi TA. RE-ATTEMPT: a new energyefficient routing protocol for wireless body area sensor networks. IJDSN. 2014;10(4):464010.

18. Sahndhu MM, Javaid N, Imran M, Guizani M, Khan ZA, Qasim U. BEC: A novel routing protocol for balanced energy consumption in Wireless Body Area Networks. In2015 International Wireless Communications and Mobile Computing Conference (IWCMC) 2015 Aug 24 (pp. 653-658). IEEE.

19. Sandhu MM, Javaid N, Akbar M, Najeeb F, Qasim U, Khan ZA, editors. FEEL: forwarding data energy efficiently with load balancing in wireless body area networks. 2014 IEEE 28th International Conference on Advanced Information Networking and Applications; 2014: IEEE.

20. Lee YH, Lee KO, Lee HJ, Kusdaryono A, editors. CBERP: Cluster based energy efficient routing protocol for wireless sensor network. Proc 12th Int 1 Conf Networking, VLSI and Signal Processing University of Cambridge UK; 2010.

21. Yi C, Wang L, Li Y. Energy efficient transmission approach for WBAN based on threshold distance. IEEE sens J . 2015;15(9):5133-41.

22. Qureshi KN, Bashir F, Abdullah AH, editors. An energy and link aware next node selection protocol for body area networks. Information Networking (ICOIN), 2018 International Conference on; 2018: IEEE. 
الحلول والتحديات الحديثة المتعلقة بالطاقة في الشبكات اللاسلكية لمنطقة الجسم مع التقتيات المتكاملة: التطبيقات والمنظورات المبكات

2 كاثف ناصر القريشي 2

\author{
يسرى عبد الصاحب سيف الاين 1 \\ 1قسم علوم الحاسب، كلية العلوم للبنات، جامعة بغداد، بغداد، العر اق.

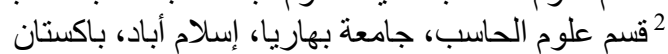

الخلاصة: في هذه الورقة، بحثنا في بعض أحدث بروتوكو لات التوجيه الموفرة للطاقة لثبكات منطقة الجسم اللاسلكية. شهدت هذه التكنولوجيا

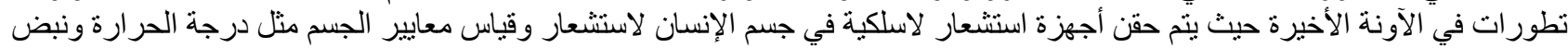

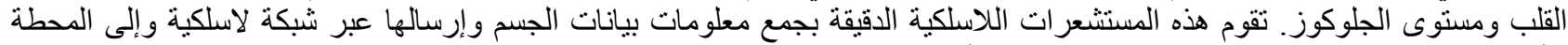

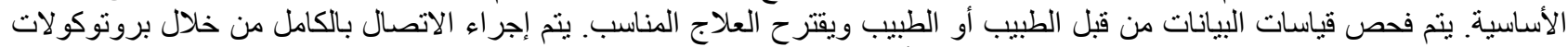

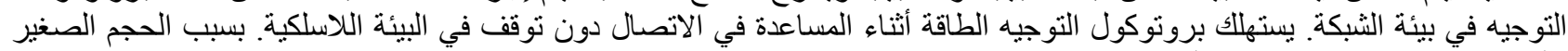

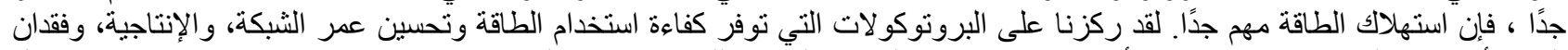

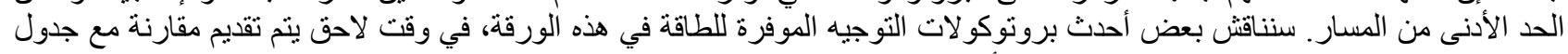

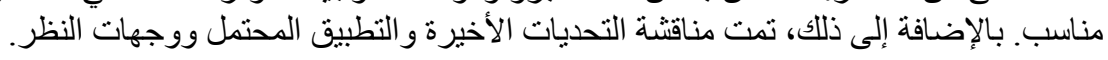
الكلمات المفتاحية: رؤساء الكتلة ،كفاءة استخدام الطاقة ،بروتوكو لات التوجيه ، WSN،WBAN 